\title{
Plasma Oxytocin in Children with Autism and Its Correlations with Behavioral Parameters in Children and Parents
}

\author{
Veronika Marcincakova Husarova ${ }^{1,2}$, Silvia Lakatosova', Anna Pivovarciova', Katarina Babinska', \\ Jan Bakos ${ }^{1}$, Jaroslava Durdiakova1, Aneta Kubranska', Igor Ondrejka ${ }^{2}{ }^{\otimes}$, and Daniela Ostatnikova ${ }^{1}$ \\ ${ }^{1}$ Institute of Physiology, Medical Faculty Comenius University, Bratislava, Slovakia \\ ${ }^{2}$ Clinic of Psychiatry, Martin University Hospital and Jessenius Faculty of Medicine, Comenius University, Martin, Slovakia
}

Objective Oxytocin (OT) has been implicated to play an important role in autism spectrum disorders (ASD) etiology. We aimed to find out the differences in plasma OT levels between children with autism and healthy children, the associations of OT levels with particular autism symptoms and the associations of particular parental autistic traits with their ASD children OT levels.

Methods We included 19 boys with autism and 44 healthy age-matched boys. OT levels were analyzed by ELISA method. Children with autism were scored by Childhood Autism Rating Scale and Autism Diagnostic Interview (ADI), adjusted research version. Autism Spectrum Quotient (AQ), Systemizing Quotient (SQ) and Empathizing Quotient were completed by parents of children with autism.

Results Children with autism had significantly lower plasma OT levels than controls. OT levels positively correlated with ADI Reciprocal Interaction and Communication scores. AQ and SQ of fathers positively correlated with children plasma OT level.

Conclusion Our results support the hypothesis of OT deficiency in autism. The "paradoxical" associations of OT levels and social skills in children with autism indicate disturbances at various levels of OT system. We first reported associations of OT levels in children with autism and behavioral measures in fathers indicating that OT abnormalities stay between parental autistic traits and autism symptoms in their children.

Psychiatry Investig 2016;13(2):174-183

Key Words Autism, Oxytocin, Parents, Autism spectrum quotient, Systemizing quotient.

\section{INTRODUCTION}

Autism spectrum disorders (ASD) are neurodevelopmental disorders characterized by derangement in social-communicative abilities, emotional development, integrative and executive functions relatively to the development of other psychological functions. The symptoms include delayed/abnormal verbal and nonverbal communication, social contact avoidance and restricted or stereotyped play, interests and behavior. Autism is highly heritable with the $60-96 \%$ concordance in monozygotic twins compared to $0-23 \%$ in dizygotic twins. ${ }^{1-3}$ In spite of the

Received: January 25, 2015 Revised: May 8, 2015

Accepted: June 4, 2015 Available online: January 11, 2016

$\triangle$ Correspondence: Igor Ondrejka, MD, $\mathrm{PhD}$

Clinic of Psychiatry, Jessenius Faculty of Medicine, Comenius University, Kollárova 2, Martin 03659, Slovakia

Tel: +421-434203398, Fax: +421-434133271

E-mail: Igor.Ondrejka@jfmed.uniba.sk

(a) This is an Open Access article distributed under the terms of the Creative Commons Attribution Non-Commercial License (http://creativecommons.org/licenses/by$\mathrm{nc} / 3.0$ ) which permits unrestricted non-commercial use, distribution, and reproduction in any medium, provided the original work is properly cited. extensive research, the etiology of autism is largely unknown.

Oxytocin (OT) has been implicated to play an important role in autism etiology due to its effects on emotional and social behavior..$^{4-8}$ Oxytocin, as a product of the OT gene located at human gene locus $20 \mathrm{p} 13^{9}$ is synthesized in magnocellular neurons in the hypothalamic paraventricular and supraoptic nuclei and transported axonally into neurohypophysis. ${ }^{10} \mathrm{OT}$ production has been also reported in peripheral tissues, namely uterus, placenta, amnion, corpus luteum, testis, gut and heart. ${ }^{11,12}$ Plasma oxytocin in humans has not shown the diurnal variations. ${ }^{13}$ Its importance in attachment, maternal behavior, ultrasonic vocalization to social isolation and affiliative and social behavior has been demonstrated in animal studies.,14-16 In healthy humans, intranasal OT administration enhanced trust, perception of faces, increased gaze to eye region and improved the identification of emotions from the eyes, as reviewed in Yamasue et al. ${ }^{17}$ The overlap of the central OT effects and their deficits in ASD lead to the hypotheses of OT anomalies in ASD which have been proved in several studies. The 
group of children with autism had significantly lower plasma OT levels than the control group, ${ }^{18-20}$ moreover subjects with autism had lower levels of the bioactive amidated form and higher OT precursor levels indicating the alterations in the OT peptide forms processing. ${ }^{10}$ However, the aforementioned studies differ in the results of the associations of OT levels and autism symptoms. Modahl et al. ${ }^{18}$ have reported the positive association of OT with social and developmental measures in the group of children without autism, whereas in the group of children with autism, OT has been negatively associated with daily living skills, personal care and community skills. On the contrary, Al-Ayadhi ${ }^{19}$ and Miller et al. ${ }^{20}$ have not found the significant correlation of OT and degree of autism symptoms. The hypotheses of OT defective function in autism are supported by the studies in which OT was administered to individuals with autism with the improvement of social skills. OT infusion reduced repetitive behavior and improved the affective speech comprehension in adults with autism and Asperger disorder. ${ }^{21,22}$ Intranasal OT administration in adults with autism improved the measures of social cognition ${ }^{23}$ and increased the interactions with the most socially cooperative partner in a simulated ball game, enhanced the feelings of trust and increased the gaze time over the video-displayed eye region in a pictures of faces. ${ }^{24}$ Results of these studies indicate that derangements of the endocrine OT system play an important role in autism etiology, however the contradictions in the associations of autism symptoms and OT plasma levels must be elucidated. We aimed to support the present knowledge by the finding of the differences in plasma OT levels between children with autism and typically developing children and the associations of OT levels with the scores of instruments evaluated by clinicians and parents.

Autism spectrum disorders are considered to be a continuum from mild autistic traits, distributed through the normal population, with the same cognitive determinants as autistic disorders. ${ }^{25}$ This milder phenotype with subclinical differences in social skills, communication abilities and personality traits is generally described as broader autism phenotype (BAP), which has been widely reported to be present in relatives of people with ASD in higher rates than in healthy people without an ASD relative. ${ }^{26}$ Autism Spectrum Quotient (AQ), Systemizing Quotient (SQ) and Empathy Quotient (EQ) are the instruments extensively used to evaluate the autistic traits within normal population..$^{27-31}$ Supporting the high genetic component of autism, the different subscales of AQ have been found to be scored higher in parents of children with autism compared to control parents. ${ }^{27,32-34}$

To our best knowledge, no study has evaluated the OT associations with the particular traits of BAP within the non-autistic population or parents of children with ASD. The aforemen- tioned studies' results of decreased plasmatic OT in children with autism and improvement of social skills after OT administration in both healthy and individuals with autism suggest that OT could be the linking component between parental autistic traits and child's ASD symptoms, particularly those including social dysfunction. We aimed to find out the associations of the particular autistic traits evaluated by AQ, SQ and EQ in parents with the OT levels in their ASD children.

Our study aimed to elucidate 3 questions: 1) Do plasmatic OT levels differ between children with autism and control healthy typically developing children? 2) Are plasmatic OT levels in children with autism associated with the severity of particular autism symptoms, and if yes, which of them? 3) Are plasmatic OT levels in children with autism associated with autistic traits of their parents?

\section{METHODS}

\section{Participants}

We recruited 19 boys with the diagnosis of childhood autism and 44 healthy control typically developing boys between ages of 2 and 9. Subjects with autism and control subjects were group-matched for chronological age: boys with autism mean age $=56.7$ months, $\mathrm{SD}=25.4$ months; control boys mean age= 58.9 months, $\mathrm{SD}=23.0$ months. Children with autism were recruited from the local Autism Centre for children in Bratislava, Slovakia. All boys with autism were diagnosed as meeting criteria for ICD-10 childhood autism by a clinical child psychologist with the cooperation of a child psychiatrist, who confirmed all diagnoses. Only children with IQ $\geq 70$ and without any other psychiatric disorder were included into the study. We recruited only boys with autism classified as aloof according to the Wing's classification. ${ }^{35}$ Children with other pervasive developmental disorders and children classified as passive or active-but-odd ${ }^{35}$ were not recruited, as well as girls due to clinical and gender homogeneity of sample. All subjects were medication-free. Control subjects were recruited through local pediatrician ambulance after regular pediatric examination or mild physical condition due to which they attended pediatrician. All subjects were at the time of blood sample intake healthy and without any known physical condition that was confirmed by pediatrician. All control subjects were without any psychiatric condition confirmed by child psychiatrist according to their examinations and parent interview. All control subjects had normal functioning in a regular kindergarten or elementary school. No control subject had delay in speech and language or psychomotor development as per parent interview.

Parents of children with autism were recruited at the same time and place as their children during their visit in Autistic Centre after the diagnostic procedure of their child, during the 
four-month period September-December 2012. Fourteen mothers and 13 fathers participated in the study. Four mothers and 4 fathers did not assent to participate in the study, 2 fathers did not live with or did not contact their families, the mother of one boy was not alive. The study was explained to parents in Autistic Centre and the questionnaires were sent by e-mail to those consenting to the study. Parents were asked to send the completed questionnaires by e-mail. All participating parents send the completed questionnaires within 2 weeks. The age of mothers was: mean $=34.6$ years, $S D=7.7$ years, the age of fathers was: mean $=38.6$ years, $\mathrm{SD}=5.5$ years. The education of 4 mothers was graduate, 8 had high school, and 2 elementary school education. Five fathers had graduate and 8 high school education. All parents had no history of psychiatric treatment, except one mother with depressive disorder according to her reference.

Written informed consent was obtained from all parents of participating children, parents of children with autism signed the written consent both for themselves and their children. The protocol was approved by the Ethics Committee of Faculty of Medicine, Comenius University. The study conformed to the code of ethics stated in the Declaration of Helsinki.

\section{Plasma oxytocin measurement}

Three $\mathrm{mL}$ of venous blood were taken from children with autism in the local Neurological Centre for Children and Adults in Bratislava. Blood of control children was taken by their pediatrician. The blood samples of all children were obtained during the same daily interval from 8.00-9.00 am. Immediately after samples intake, blood was centrifuged. After 10 minutes centrifugation at 3000 RPM, plasma was taken with addition of protease inhibitor aprotinin (Sigma Aldrich). Plasma samples with aprotinin were stored at $-20^{\circ} \mathrm{C}$ until OT measurement. Plasma OT levels were measured using ELISA method according to manufacturer's instructions (Enzo Life Sciences). All OT measurements were performed in the laboratory of Institute of Physiology, Comenius University in Bratislava.

\section{Psychological measures in children and parents}

All children with autism were tested using The Childhood Autism Rating Scale (CARS) evaluated by child clinical psychologist with the cooperation of child psychiatrist and Autism Diagnostic Interview (ADI), the adjusted research version, which was filled by child psychiatrist as per interview with parents. Parents of children with autism were asked to fulfill Autism Spectrum Quotient (AQ), Systemizing Quotient (SQ) and Empathy Quotient (EQ) which were sent to them by e-mail.

$\mathrm{CARS}^{36}$ is a behavioral assessment scale for diagnostics of autism, appropriate for children of all ages. It is designated to identify children with autism and for differential diagnostics of autism and other developmental disorders. CARS includes 15 items rated on a 7-point scale with the evaluation in 4 degrees-non-autistic, mild autistic, middle autistic and severe autistic child. The range of scores on the CARS is 15-60. Scores of 30 or higher are in the autism range. Independent psychometric support for the CARS is excellent. CARS has better diagnostic validity than other autism rating scales with high criterionrelated validity, inter-rater and test-retest reliability and internal consistency. ${ }^{37-40}$

$\mathrm{ADI}^{41}$ is a semi-structured interview for parents, who respond to the questions about patient's behavior. Their responses were combined with the clinical observations of child psychiatrist who examined the child before the interview. We used the adjusted ADI version for research ${ }^{42}$ with 35 items in 4 content areas: social/reciprocal interaction, communication, speech and language and restricted/repetitive behavior, rated on 3 or 4 point scale. The research version of ADI is shorter and more easily performable that the current version of ADIR. Social interaction area includes 13 items which are generally scored 0-no evidence of abnormality, 1-some evidence of abnormality, 2-evidence of marked abnormality, 3-very high abnormality. This area includes items of eye contact, social smile, mimics, imaginative play, imitative play, interest in other children, play in peer group, expression of sympathy, use of other person's body part, joint attention and pleasure. The total score of this area ranges from 0 to 39 . The communication area includes 7 items about pointing on objects, gestures, expression of agreement and disagreement by head wagging, spontaneous imitation, imaginative and imitative play. Two items are scored in 3-point scale, namely expression of agreement and disagreement by head wagging (generally 0 -normal occurrence, 1 -sometimes, 2-never), other items are scored in 4-point scale (generally 0-no evidence of abnormality, 1-some evidence of abnormality, 2-evidence of marked abnormality, 3-very high abnormality). The total score of this area ranges from 0 to 19 . The speech and language area includes 7 items about the general speech level, reciprocal conversation, small talk, stereotypes in speech, inadequate questions/arguments, pronouns exchange and neologisms/idiosyncrasies. General speech level is scored 0-2 (0-functional use of spontaneous, echolalic or stereotyped speech, 1-functional use of spontaneous, echolalic or stereotyped speech is not present, 2-child uses less than 5 words or signs of verbal communication are not present daily) and small talk 0-3 (generally 0-no evidence of abnormality, 1-some evidence of abnormality, 2-evidence of marked abnormality, 3-very high abnormality). Other items within this area are scored 0-3 (generally 0-no evidence of abnormality, 1-some evidence of abnormality, 2-evidence of marked abnormality, 3-very high abnormality). The total score of this area ranges from 0 to 20 . The area of restricted and repetitive behavior includes 8 items about 
restricted interests, bizarre occupation, ritualized verbalization, compulsions/rituals, manierisms with fingers/hand, complex manierisms, non-functional objects use and bizarre sensoric occupation. All items are scored 0-3 (generally 0-no evidence of abnormality, 1-some evidence of abnormality, 2-evidence of marked abnormality, 3-very high abnormality), except bizarre sensoric occupation which can be scored 0-2 (0-no signs, 1-one or two bizarre occupations are present regularly and 2-marked bizarre sensoric occupation which takes a considerable time or restricts in the objects use in adequate way). The total score of this area ranges from 0 to 23 . The maximum total score is 101 points. As we wanted to reveal the associations of the actual particular symptoms of autism and the level of oxytocin, independently of developmental age, we used the current scores of ADI.

$\mathrm{AQ}$ is a self-administered questionnaire designated to quantify the autistic traits in adults with normal intelligence. It has been shown to have a good test-retest and inter-rater reliability. ${ }^{43}$ It shows good consistency across different age groups ${ }^{43-45}$ and good cross-cultural stability. ${ }^{32,46-51}$ AQ contains 50 statements and the respondent can "definitely agree", "slightly agree", "slightly disagree" and "definitely disagree". Fifty questions include 5 different areas: social skill, attention switching, attention to detail, communication and imagination. Twenty-four items confirm and 26 deny autistic traits. The 2 of 4 responses are scored 1 point when a response confirms autistic traits. The higher score represents the greater autistic traits. The possible maximum score is 50 . A cut-off value for a clinical population has been suggested to be 26 and for general population $32.43,52$

SQ and EQ are based on the Baron-Cohen's empathizingsystemizing theory and the extreme male brain theory in autism. ${ }^{53}$ Systemizing is according to Baron-Cohen defined as a drive to analyze the variables in a system and to derive the underlying rules that govern the behavior of a system, ${ }^{28}$ which is not related to intelligence. ${ }^{54}$ Empathizing is the drive to identify another person's emotions and thoughts and to respond to these with an appropriate emotion. ${ }^{28}$ Both SQ and EQ are self-reported questionnaires which have shown good validity and reliability, high internal consistency across different age groups ${ }^{28-30,55}$ and cross-cultural stability. ${ }^{56} \mathrm{EQ}$ and SQ scores have been found to be successful predictors for AQ score. ${ }^{57}$ We used the versions for adults.

SQ contains 60 items, 40 of them are systemizing, 20 are control items. The respondent can "definitely agree", "slightly agree", "slightly disagree" and "definitely disagree". The systemizing items can be scored 0,1 or 2 points, the maximum possible score is $80 .^{28}$

EQ contains 60 items, 40 empathy and 20 control items. The respondent can "definitely agree", "slightly agree", "slightly disagree" and "definitely disagree". The empathizing items can be scored 0,1 or 2 points, the maximum possible score is $80 .^{29}$ $\mathrm{AQ}, \mathrm{EQ}$ and SQ questionnaires were downloaded from Autism Research Centre website http://www.autismresearchcentre.com/ with kind permission of the authors and translated into Slovak language.

\section{Statistical analysis}

We used the two-tailed unpaired t-test with Welch's correction for group differences in plasma OT levels between children with autism and healthy children. We used Pearson correlation coefficients to correlate plasma OT levels with CARS, $\mathrm{ADI}$ and ADI subscales scores and plasma OT levels with AQ, SQ and EQ of parents. Linear regression was used to exclude possible confounding variables in significant correlations of parental behavioral scores with plasma OT levels in their children with autism. The extreme values exceeding mean \pm 2 SD were excluded from correlation analyses. The significance level was set at $\mathrm{p}<0.05$.

\section{RESULTS}

\section{Plasma oxytocin levels group differences}

We found a high statistically significant difference in plasma OT levels between groups $(t=3.71, p=0.0004)$. Descriptive statistics and group differences for OT levels are presented in Table 1.

\section{Plasma oxytocin levels and severity of particular autistic symptoms}

We excluded 1 child for OT extreme values ( $\geq$ mean \pm 2 SD) from correlation analyses. We also did not include this value into the correlation analyses with parental behavioral measures. We found the significant positive correlation of plasma OT levels and ADI reciprocal interaction and communication subscales. We did not find the significant correlations of plasma OT levels nor with ADI speech/language and restricted/repetitive behavior subscale score, neither with the CARS score or ADI total score. Descriptive statistics of scores of children with autism and correlations with plasma OT levels are presented in Table 2.

Table 1. Plasma oxytocin levels in children with autism and controls $(\mathrm{pg} / \mathrm{mL})$

\begin{tabular}{lcc}
\hline & $\begin{array}{c}\text { Children with autism } \\
(\mathrm{N}=19)\end{array}$ & $\begin{array}{c}\text { Controls } \\
(\mathrm{N}=44)\end{array}$ \\
\hline Mean (SD) & $124.10(90.59)$ & $267.77(212.37)^{*}$ \\
Median & 122.11 & 202.68 \\
Range & $31.77-314.35$ & $33.21-898.76$ \\
\hline
\end{tabular}

$*_{\mathrm{t}=3.76, \mathrm{p}=0.0004}$ 


\section{Plasma oxytocin levels and parental measures}

We excluded 1 father for the extreme values $(\geq$ mean \pm 2 $\mathrm{SD}$ ) of the $\mathrm{AQ}$ imagination subscore and 1 mother for the $\mathrm{AQ}$ total score, AQ social skill, attention switching, imagination and communication subscore from correlation analyses. We found significant positive correlations of plasma OT levels in children and fathers' AQ and SQ scores. The linear regression showed the significant relationships between these variables $\left(\mathrm{F}_{\mathrm{AQ}}=8.258, \mathrm{p}_{\mathrm{AQ}}=0.021 ; \mathrm{F}_{\mathrm{SQ}}=7.324, \mathrm{p}_{\mathrm{SQ}}=0.020\right)$. We did not find any significant correlation of children plasma OT levels and any of fathers' $\mathrm{AQ}$ subscale score, however there was the positive trend $(\mathrm{p}<0.09)$ for social skill, attention to detail and communication areas. We did not find any significant correlations between plasma OT levels and fathers' EQ score. We did not find any significant correlation between plasma OT levels and mothers' SQ and EQ score, however mothers' AQ score had a trend to positive relationship. We did not find the correlation of any of mothers' AQ subscales and children OT level. Descriptive statistics of parental measures and correlations with their children plasma OT levels are presented in Table 3.

\section{DISCUSSION}

We found significantly lower plasma OT levels in the group

Table 2. Behavioral scores of children with autism and pearson correlations with oxytocin plasma levels

\begin{tabular}{lcc}
\hline & Score mean (SD) & Pearson $\mathrm{r}$ \\
\hline ADI & $49.6(16.1)$ & 0.45 \\
ADI reciprocal interaction & $21.9(7.9)$ & $0.60^{*}$ \\
ADI communication & $12.0(4.1)$ & $0.55^{*}$ \\
ADI speech and language & $6.8(2.8)$ & 0.21 \\
ADI restricted/repetitive behavior & $8.2(4.6)$ & -0.14 \\
CARS & $48.6(6.4)$ & 0.21 \\
\hline
\end{tabular}

${ }^{*} \mathrm{p}<0.05$. ADI: Autism Diagnostic Interview, CARS: Childhood Autism Rating Scale of children with autism compared to age-matched healthy controls. We confirmed the results of previous studies ${ }^{18-20}$ supporting the hypothesis of altered endocrine OT system in autism. However, our finding of significant positive correlation of plasma OT levels and ADI reciprocal interaction and communication subscales scores indicates that autism symptoms are not negatively associated with OT levels, on the contrary we found the opposite pattern (higher OT levels were connected with more severe autism symptoms). This pattern is similar to the finding of Modahl et al.. ${ }^{18}$ in which OT levels were negatively associated with socialization items of The Vineland Adaptive Behavior Scales with the strongest correlation with items related to imitation, while in the group of normal controls higher OT levels corresponded with greater interaction skill and daily living skills. ${ }^{18}$ Thus it seems that OT levels are associated with particular ASD symptoms connected with social abilities including reciprocal interaction, imitation and skills to express the needs, however the relationship between these abilities and OT is opposite to that in people without autism spectrum disorder. ${ }^{18}$ The association of the symptoms connected with social skills reflects the OT importance in social functions reported before in animal and human studies, ${ }^{4,14-17}$ however it indicates that dysfunction in OT system is related particularly to social impairments in ASD. Furthermore, the negative relationship between OT plasma levels and social skills could reflect more extensive abnormalities at various levels in OT endocrine system. The deficits in transcription of the OT gene or the alterations in the OT peptide forms processing could explain lower OT levels in ASD, however the opposite relationship between social skills and OT levels could reflect the OT receptor (OXTR) abnormalities with the compensatory increase in OT levels. This hypothesis is supported by the findings of both OT gene and OXTR gene polymorphisms associated with ASD. The $\mathrm{CD} 38$ (coding a trans-membrane protein engaged in OT secretion) polymorphisms have been documented in relationship with the ASD pathophysiology in

Table 3. Parental behavioral scores and correlations with plasma oxytocin levels in their children with autism

\begin{tabular}{|c|c|c|c|c|}
\hline & \multicolumn{2}{|c|}{ Mothers $(\mathrm{N}=14)$} & \multicolumn{2}{|c|}{ Fathers $(\mathrm{N}=13)$} \\
\hline & Score mean (SD) & Pearson $r$ & Score mean (SD) & Pearson $\mathrm{r}$ \\
\hline AQ & $14.7(9.7)$ & $0.56^{\dagger}$ & $13.3(6.3)$ & $0.73^{*}$ \\
\hline AQ social skill & $2.3(2.7)$ & 0.39 & $1.8(1.4)$ & $0.59^{\dagger}$ \\
\hline AQ attention switching & $2.9(2.6)$ & -0.04 & $2.7(1.3)$ & 0.27 \\
\hline AQ attention to detail & $3.3(1.3)$ & 0.35 & $3.5(1.9)$ & $0.58^{\dagger}$ \\
\hline AQ communication & $4.2(2.3)$ & 0.43 & $3.2(2.1)$ & $0.56^{\dagger}$ \\
\hline AQ imagination & $1.7(2.1)$ & 0.41 & $2.0(1.9)$ & 0.12 \\
\hline EQ & $45.1(10.8)$ & 0.12 & $39.0(11.3)$ & -0.39 \\
\hline SQ & $22.8(8.4)$ & -0.36 & $33.4(6.5)$ & $0.65^{*}$ \\
\hline
\end{tabular}

${ }^{*} \mathrm{p}<0.05,{ }^{\dagger} \mathrm{p}<0.09$ (trend). AQ: Autism Spectrum Quotient, EQ: Empathizing Quotient, SQ: Systemizing Quotient 
both animal ${ }^{58}$ and human ${ }^{59,60}$ studies. The polymorphisms in the OXTR gene have been significantly associated with ASD in the Chinese, Caucasian and Japanese populations. ${ }^{6-64}$ The OXTR gene polymorphisms have been also connected with autism spectrum disorders on high-functioning level with the association to social interaction and communication deficits. ${ }^{65}$ Furthermore, the genomic deletion containing the OXTR in proband with autism and his mother with obsessive-compulsive symptoms and OXTR epigenetic misregulation by DNA methylation in proband's affected sibling have been shown. ${ }^{66}$ Thus, the ASD social deficits could be represented by the combination of abnormalities at various levels of OT system including both lower plasma OT levels and OXTR gene abnormalities with the compensatory increase in plasma OT, but insufficient due to OT gene or OT molecule processing derangements. The future studies should focus on the relationships between plasma OT levels and OXTR gene polymorphisms in the same probands with autism and their relations to particular autism symptoms, compared to individuals without autism.

We found significant positive correlations of plasma OT levels in children with autism and fathers' SQ and AQ scores with the positive trend for social skill, attention to detail and communication areas. To our best knowledge, this is the first evidence of parental behavioral measures' associations with OT level of their children with autism. These findings support our hypothesis that OT is the linking component between the level of parental and children autistic traits, predominantly those concerning social abilities. Moreover, this relationship has the same pattern as the relationship between behavioral measures of children with autism, namely social interaction and communication and their OT level. The possible explanation of these associations includes the theory of the extreme male brain in autism ${ }^{53}$ and oxytocin-testosterone interactions. The extreme male brain, with its phenotypic continuum from mild autistic traits to severe ASD, assumes better systemizing than empathizing due to elevated fetal testosterone levels. ${ }^{53}$ This theory is supported by the findings of lower 2D:4D ratio in individuals with autism ${ }^{67-70}$ which is considered to be a marker of prenatal testosterone concentration, ${ }^{71}$ increased rate of testosterone-related medical conditions in females with ASD and mothers of ASD children ${ }^{72}$ and correlations of salivary testosterone with $\mathrm{AQ}$ in a group of males and females. ${ }^{73}$ The testosterone production has been reported to be stimulated by OT in cultures of isolated adult rat Leydig cells, ${ }^{74}$ after subcutaneous OT injections in female goat $\mathrm{s}^{75}$ and has been confirmed in healthy men after intranasal OT application. ${ }^{76}$ To our best effort, we did not find the evidence about the enhancing effects of OT on testosterone production also prenatally. We hypothesize that in healthy individuals higher prenatal OT could lead to higher testosterone resulting in greater autistic traits, still within subclinical form. Prenatal testosterone could have the feedback effects on OT system. It has been previously found that steroid hormones have the regulative enhancing effects on brain OXTR gene expression and central OT binding, which are region-specific. ${ }^{77-81}$ To our best knowledge, no study has directly documented the prenatal testosterone effects on OT production in supraoptic and paraventricular nucleus or OXTR sensitivity, however intranasal OT in healthy men induced the group-serving tendencies only in those with higher fetal testosterone, according to their $2 \mathrm{D}: 4 \mathrm{D}$ ratio, ${ }^{82}$ which indicates the different responsiveness to OT mediated by prenatal testosterone exposure. We hypothesize that whereas prenatal testosterone could have enhancing region-specific effects on postnatal OXTR sensitivity, gene expression or central OT binding in healthy individuals, the prenatal hypertestosteronism resulting in autism could lead to oxytocin level decrease through the negative feedback by down-regulation of OT or OXTR gene expression with the effect on postnatal OT plasma level decrease or decrease in OXTR sensitivity. Despite the down-regulation of genes expression, the inherited OT or OXTR gene polymorphisms could conserve the proportional OT production in parents and children, which could be partially proven if father's blood samples were available for OT measurements. This hypothesis explains why we found the positive correlation between plasma OT levels in children with autism and AQ and SQ of their fathers, despite the decreased OT in children with autism compared to healthy controls. In other words, the non-autistic fathers with higher prenatal OT could have higher prenatal testosterone leading to greater autistic traits. Their children with autism with prenatal hypertestosteronism could have down-regulated OT gene leading to decreased postnatal OT level. However the association between father's and child's OT production could be proportional, resulting to our finding that children with autism with higher OT have fathers with greater autistic traits. Concurrently, this hypothesis indirectly indicates the OT role in the positive associations of the parental autistic traits severity and autism symptom severity in affected children documented before. ${ }^{83-85}$

Furthermore, we found the positive correlation of children OT level and AQ and SQ only in fathers, not mothers. In spite of the fact that there was a positive trend for $\mathrm{AQ}$ in mothers, the relationship of maternal autistic traits and children OT level was still lower than that of paternal autistic traits. Moreover, we did not find the trend to correlation for any of mothers' $\mathrm{AQ}$ subscale as we did in fathers. This result can be associated with the previous finding of a study in which only father's (but not mother's) BAP severity predicted the severity of autistic symptoms of affected child. ${ }^{85}$ Explanation of these findings can lean on an evolutionary hypothesis for autism which proposes the imbalances in the outcomes of intragenomic conflict between 
maternally and paternally expressed genes. ${ }^{86}$ Based on the extensive evidence from genetic studies, authors of this hypothesis proposed the imprinted brain theory of autism which is caused by imbalances that involve increased genetic, neurological and behavioral effects of paternal brain at a cost of maternal brain. According to this theory, father's genes are expected to motivate self-interested behavior which might explain why paternal genes are preferentially expressed in hypothalamus, amygdala and other parts of limbic system involved in basic drives, appetites and emotions. ${ }^{86}$ This hypothesis, covering also the Baron-Cohen's extreme male brain theory, ${ }^{53}$ elucidates the associations of predominantly father's autistic traits with the child's level of OT, produced in a region of paternal genes preferential expression. However, our study was limited to the sample of boys, excluding girls with autism, thus we cannot conclude if this hypothesis can be applied to the whole population with ASD. Further studies must be done to elucidate the relationship between OT levels also in girls with autism and maternal and paternal behavioral measures.

Our results are preliminary and should be confirmed in higher number of children with autism and their parents. Except the small sample sizes, our study has several limitations which must be noted. First, we included only children classified as aloof according to the Wing's typology. ${ }^{35}$ Modahl et al. ${ }^{18}$ have found that aloof and active-but-odd subgroups did not differ significantly in OT levels, however the correlation of OT level and communication, daily living and socialization scores has been reported only in aloof group, but not active-butodd. ${ }^{18}$ Our results support this finding, however future research must be done to elucidate the relationships between OT level and symptoms of other ASD subgroups. Second, we included only boys precluding the generalization of our results to female subjects. Third, we did not quantify behavioral parameters in parents of healthy control children, thus we cannot conclude if the associations of children OT level and fathers' AQ and SQ are present in population with autism exclusively. Fourth, we evaluated the OT levels in plasma. It is well known that the sources of plasmatic OT may be central, from hypothalamic magnocellular neurons leading to neurohypophysis and directly releasing from magnocellular circuitry into capillaries and peripheral, including gut, testis and heart in male subjects. ${ }^{11,12}$ Despite the findings of increased plasma OT levels after social stimuli in humans, ${ }^{87,88}$ there have been documented the concentration differences between OT levels in plasma and cerebrospinal fluid ${ }^{89}$ However, even the plasma OT level probably does not reflect the OT release from parvocellular neurons terminating in limbic system, it can reflect the coordinated release by magnocellular neurons which might be activated in the context of social stimuli. ${ }^{90}$ We have to take into account also the aforementioned peripheral sources which may contribute to plasma OT level and its signaling through the afferent visceral branches that can be registered as emotional stimuli in the brain. ${ }^{90}$ However, the fact that children OT levels correlated with behavioral characteristics of fathers indicates that they could reflect the OT levels in CNS. As it has been shown that autism symptoms significantly improve during $4-5$ year period ${ }^{91}$ and plasma oxytocin level decreases with age, ${ }^{92}$ further studies should also investigate the relationships between symptoms of autism and oxytocin in the association with aging in the population with and without autism.

Despite the limitations, our pilot study brought the novel results. We brought the further evidence of decreased plasma OT levels in children with autism which supports the OT deficiency hypothesis in autism. We reported the "paradoxical" associations of OT levels and social skills in children with autism which could indicate the disturbances at various levels in OT endocrine system. We first reported the associations of OT levels in children with autism and behavioral measures in fathers only, namely AQ and SQ, which indicates that OT is the linking component between the level of parental autistic traits and social abilities of their children with autism, moreover supports the evolutionary hypothesis of intragenomic conflict between maternally and paternally expressed genes in autism. Further research with extended number of child-parents pairs has to be done to confirm our preliminary results.

\section{Acknowledgments}

Authors thank to all parents and their children for participation in the study. The study was supported by the following grants: APVV-0254-11, APVV-0253-10, VEGA- 1/0066/12 and UK 67/2013.

\section{REFERENCES}

1. Ritvo ER, Freeman BJ, Mason-Brothers A, Mo A, Ritvo AM. Concordance for the syndrome of autism in 40 pairs of afflicted twins. Am J Psychiatry 1985;142:74-77.

2. Bailey A, Le Couteur A, Gottesman I, Bolton P, Simonoff E, Yuzda E, et al. Autism as a strongly genetic disorder: evidence from a British twin study. Psychol Med 1995;25:63-77.

3. Steffenburg S, Gillberg C, Hellgren L, Andersson L, Gillberg IC, Jakobsson G, et al. A twin study of autism in Denmark, Finland, Iceland, Norway and Sweden. J Child Psychol Psychiatry 1989;30:405-416.

4. Neumann ID. Brain oxytocin: a key regulator of emotional and social behaviours in both females and males. J Neuroendocrinol 2008;20: 858-865.

5. Stavropoulos KK, Carver LJ. Research review: social motivation and oxytocin in autism - implications for joint attention development and intervention. J Child Psychol Psychiatry 2013;54:603-618.

6. Gurrieri F, Neri G. Defective oxytocin function: a clue to understanding the cause of autism? BMC Med 2009;7:63.

7. Sauer C, Montag C, Worner C, Kirsch P, Reuter M. Effects of a common variant in the CD38 gene on social processing in an oxytocin challenge study: possible links to autism. Neuropsychopharmacology 2012;37: 1474-1482.

8. Modahl C, Fein D, Waterhouse L, Newton N. Does oxytocin deficiency mediate social deficits in autism? J Autism Dev Disord 1992;22:449451. 
9. Rao VV, Loffler C, Battey J, Hansmann I. The human gene for oxytocin-neurophysin I (OXT) is physically mapped to chromosome 20p13 by in situ hybridization. Cytogenet Cell Genet 1992;61:271-273.

10. Green L, Fein D, Modahl C, Feinstein C, Waterhouse L, Morris M. Oxytocin and autistic disorder: alterations in peptide forms. Biol Psychiatry 2001;50:609-613.

11. Kiss A, Mikkelsen JD. Oxytocin--anatomy and functional assignments: a minireview. Endocr Regul 2005;39:97-105.

12. Yu Q, Ji R, Gao X, Fu J, Guo W, Song X, et al. Oxytocin is expressed by both intrinsic sensory and secretomotor neurons in the enteric nervous system of guinea pig. Cell Tissue Res 2011;344:227-237.

13. Amico JA, Tenicela R, Johnston J, Robinson AG. A time-dependent peak of oxytocin exists in cerebrospinal fluid but not in plasma of humans. J Clin Endocrinol Metab 1983;57:947-951.

14. Takayanagi Y, Yoshida M, Bielsky IF, Ross HE, Kawamata M, Onaka T, et al. Pervasive social deficits, but normal parturition, in oxytocin receptor-deficient mice. Proc Natl Acad Sci U S A 2005;102:16096-16101.

15. Jin D, Liu HX, Hirai H, Torashima T, Nagai T, Lopatina O, et al. CD38 is critical for social behaviour by regulating oxytocin secretion. Nature 2007; 446:41-45.

16. Liu HX, Lopatina O, Higashida C, Tsuji T, Kato I, Takasawa S, et al. Locomotor activity, ultrasonic vocalization and oxytocin levels in infant CD38 knockout mice. Neurosci Lett 2008;448:67-70.

17. Yamasue H, Kuwabara H, Kawakubo Y, Kasai K. Oxytocin, sexually dimorphic features of the social brain, and autism. Psychiatry Clin Neurosci 2009;63:129-140.

18. Modahl C, Green L, Fein D, Morris M, Waterhouse L, Feinstein C, et al. Plasma oxytocin levels in autistic children. Biol Psychiatry 1998;43: 270-277.

19. Al-Ayadhi LY. Altered oxytocin and vasopressin levels in autistic children in Central Saudi Arabia. Neurosciences (Riyadh) 2005;10:47-50.

20. Miller M, Bales KL, Taylor SL, Yoon J, Hostetler CM, Carter CS, et al. Oxytocin and vasopressin in children and adolescents with autism spectrum disorders: sex differences and associations with symptoms. Autism Res 2013;6:91-102.

21. Hollander E, Bartz J, Chaplin W, Phillips A, Sumner J, Soorya L, et al. Oxytocin increases retention of social cognition in autism. Biol Psychiatry 2007;61:498-503.

22. Hollander E, Novotny S, Hanratty M, Yaffe R, DeCaria CM, Aronowitz $\mathrm{BR}$, et al. Oxytocin infusion reduces repetitive behaviors in adults with autistic and Asperger's disorders. Neuropsychopharmacology 2003;28:193-198.

23. Anagnostou E, Soorya L, Chaplin W, Bartz J, Halpern D, Wasserman S, et al. Intranasal oxytocin versus placebo in the treatment of adults with autism spectrum disorders: a randomized controlled trial. Mol Autism 2012;3:16.

24. Andari E, Duhamel JR, Zalla T, Herbrecht E, Leboyer M, Sirigu A. Promoting social behavior with oxytocin in high-functioning autism spectrum disorders. Proc Natl Acad Sci U S A 2010;107:4389-4394.

25. Best CS, Moffat VJ, Power MJ, Owens DG, Johnstone EC. The boundaries of the cognitive phenotype of autism: theory of mind, central coherence and ambiguous figure perception in young people with autistic traits. J Autism Dev Disord 2008;38:840-847.

26. Gerdts J, Bernier R. The broader autism phenotype and its implications on the etiology and treatment of autism spectrum disorders. Autism Res Treat 2011;2011:545901.

27. Wheelwright S, Auyeung B, Allison C, Baron-Cohen S. Defining the broader, medium and narrow autism phenotype among parents using the Autism Spectrum Quotient (AQ). Mol Autism 2010;1:10.

28. Baron-Cohen S, Richler J, Bisarya D, Gurunathan N, Wheelwright S. The systemizing quotient: an investigation of adults with Asperger syndrome or high-functioning autism, and normal sex differences. Philos Trans R Soc Lond B Biol Sci 2003;358:361-374.

29. Baron-Cohen $S$, Wheelwright $S$. The empathy quotient: an investigation of adults with Asperger syndrome or high functioning autism, and normal sex differences. J Autism Dev Disord 2004;34:163-175.

30. Auyeung B, Allison C, Wheelwright S, Baron-Cohen S. Brief report: development of the adolescent empathy and systemizing quotients. J Autism Dev Disord 2012;42:2225-2235.

31. Wright DB, Skagerberg EM. Measuring empathizing and systemizing with a large US sample. PLoS One 2012;7:e31661.

32. Kose S, Bora E, Erermis S, Ozbaran B, Bildik T, Aydin C. Broader autistic phenotype in parents of children with autism: Autism Spectrum Quotient-Turkish version. Psychiatry Clin Neurosci 2013;67:20-27.

33. Bishop DV, Maybery M, Maley A, Wong D, Hill W, Hallmayer J. Using self-report to identify the broad phenotype in parents of children with autistic spectrum disorders: a study using the Autism-Spectrum Quotient. J Child Psychol Psychiatry 2004;45:1431-1436.

34. Scheeren AM, Stauder JE. Broader autism phenotype in parents of autistic children: reality or myth? J Autism Dev Disord 2008;38:276-287.

35. Wing L, Gould J. Severe impairments of social interaction and associated abnormalities in children: epidemiology and classification. J Autism Dev Disord 1979;9:11-29.

36. Schopler E, Reichler RJ, DeVellis RF, Daly K. Toward objective classification of childhood autism: Childhood Autism Rating Scale (CARS). J Autism Dev Disord 1980;10:91-103.

37. Ozonoff S, Goodlin-Jones BL, Solomon M. Evidence-based assessment of autism spectrum disorders in children and adolescents. J Clin Child Adolesc Psychol 2005;34:523-540.

38. Eaves RC, Milner B. The criterion-related validity of the Childhood Autism Rating Scale and the Autism Behavior Checklist. J Abnorm Child Psychol 1993;21:481-491.

39. Mayes SD, Calhoun SL, Murray MJ, Morrow JD, Yurich KK, Mahr F, et al. Comparison of scores on the Checklist for Autism Spectrum Disorder, Childhood Autism Rating Scale, and Gilliam Asperger's Disorder Scale for children with low functioning autism, high functioning autism, Asperger's disorder, ADHD, and typical development. J Autism Dev Disord 2009;39:1682-1693.

40. Rellini E, Tortolani D, Trillo S, Carbone S, Montecchi F. Childhood Autism Rating Scale (CARS) and Autism Behavior Checklist (ABC) correspondence and conflicts with DSM-IV criteria in diagnosis of autism. J Autism Dev Disord 2004;34:703-708.

41. Le Couteur A, Rutter M, Lord C, Rios P, Robertson S, Holdgrafer M, et al. Autism diagnostic interview: a standardized investigator-based instrument. J Autism Dev Disord 1989;19:363-387.

42. Pečeňák J. The Childhood Autism Diagnostics. In: Lechta V, Editor. The Diagnostics of the Impaired Communication Ability. Bad Heilbrunn/ Obb: Verlag Julius Klinkhardt; 2003, p. 312-335.

43. Baron-Cohen S, Wheelwright S, Skinner R, Martin J, Clubley E. The autism-spectrum quotient (AQ): evidence from Asperger syndrome/ high-functioning autism, males and females, scientists and mathematicians. J Autism Dev Disord 2001;31:5-17.

44. Baron-Cohen S, Hoekstra RA, Knickmeyer R, Wheelwright S. The Autism-Spectrum Quotient (AQ)--adolescent version. J Autism Dev Disord 2006;36:343-350.

45. Auyeung B, Baron-Cohen S, Wheelwright S, Allison C. The Autism Spectrum Quotient: Children's Version (AQ-Child). J Autism Dev Disord 2008;38:1230-1240.

46. Wakabayashi A, Baron-Cohen S, Wheelwright S, Tojo Y. The AutismSpectrum Quotient (AQ) in Japan: a cross-cultural comparison. J Autism Dev Disord 2006;36:263-270.

47. Hoekstra RA, Bartels M, Cath DC, Boomsma DI. Factor structure, reliability and criterion validity of the Autism-Spectrum Quotient (AQ): a study in Dutch population and patient groups. J Autism Dev Disord 2008;38:1555-1566.

48. Broadbent J, Galic I, Stokes MA. Validation of autism spectrum quotient adult version in an Australian sample. Autism Res Treat 2013;2013: 984205.

49. Ruta L, Mazzone D, Mazzone L, Wheelwright S, Baron-Cohen S. The Autism-Spectrum Quotient--Italian version: a cross-cultural confirma- 
tion of the broader autism phenotype. J Autism Dev Disord 2012;42: 625-633.

50. Sonie S, Kassai B, Pirat E, Bain P, Robinson J, Gomot M, et al. The French version of the autism-spectrum quotient in adolescents: a crosscultural validation study. J Autism Dev Disord 2013;43:1178-1183.

51. Lau WY, Gau SS, Chiu YN, Wu YY, Chou WJ, Liu SK, et al. Psychometric properties of the Chinese version of the Autism Spectrum Quotient (AQ). Res Dev Disabil 2013;34:294-305.

52. Woodbury-Smith MR, Robinson J, Wheelwright S, Baron-Cohen S. Screening adults for Asperger Syndrome using the AQ: a preliminary study of its diagnostic validity in clinical practice. J Autism Dev Disord 2005;35:331-335.

53. Baron-Cohen S. The extreme male brain theory of autism. Trends Cogn Sci 2002;6:248-254.

54. Ling J, Burton TC, Salt JL, Muncer SJ. Psychometric analysis of the systemizing quotient (SQ) scale. Br J Psychol 2009;100:539-552.

55. Auyeung B, Wheelwright S, Allison C, Atkinson M, Samarawickrema N, Baron-Cohen S. The children's Empathy Quotient and Systemizing Quotient: sex differences in typical development and in autism spectrum conditions. J Autism Dev Disord 2009;39:1509-1521.

56. Wakabayashi A, Baron-Cohen S, Uchiyama T, Yoshida Y, Kuroda M, Wheelwright S. Empathizing and systemizing in adults with and without autism spectrum conditions: cross-cultural stability. J Autism Dev Disord 2007;37:1823-1832.

57. Wheelwright S, Baron-Cohen S, Goldenfeld N, Delaney J, Fine D, Smith R, et al. Predicting Autism Spectrum Quotient (AQ) from the Systemizing Quotient-Revised (SQ-R) and Empathy Quotient (EQ). Brain Res 2006;1079:47-56.

58. Higashida H, Lopatina O, Yoshihara T, Pichugina YA, Soumarokov AA, Munesue T, et al. Oxytocin signal and social behaviour: comparison among adult and infant oxytocin, oxytocin receptor and CD38 gene knockout mice. J Neuroendocrinol 2010;22:373-379.

59. Munesue T, Yokoyama S, Nakamura K, Anitha A, Yamada K, Hayashi $\mathrm{K}$, et al. Two genetic variants of CD38 in subjects with autism spectrum disorder and controls. Neurosci Res 2010;67:181-191.

60. Higashida H, Yokoyama S, Huang JJ, Liu L, Ma WJ, Akther S, et al. Social memory, amnesia, and autism: brain oxytocin secretion is regulated by NAD+ metabolites and single nucleotide polymorphisms of CD38. Neurochem Int 2012;61:828-838.

61. Wu S, Jia M, Ruan Y, Liu J, Guo Y, Shuang M, et al. Positive association of the oxytocin receptor gene (OXTR) with autism in the Chinese Han population. Biol Psychiatry 2005;58:74-77.

62. Jacob S, Brune CW, Carter CS, Leventhal BL, Lord C, Cook EH Jr. Association of the oxytocin receptor gene (OXTR) in Caucasian children and adolescents with autism. Neurosci Lett 2007;417:6-9.

63. Lerer E, Levi S, Salomon S, Darvasi A, Yirmiya N, Ebstein RP. Association between the oxytocin receptor (OXTR) gene and autism: relationship to Vineland Adaptive Behavior Scales and cognition. Mol Psychiatry 2008;13:980-988.

64. Liu X, Kawamura Y, Shimada T, Otowa T, Koishi S, Sugiyama T, et al. Association of the oxytocin receptor (OXTR) gene polymorphisms with autism spectrum disorder (ASD) in the Japanese population. J Hum Genet 2010;55:137-141.

65. Wermter AK, Kamp-Becker I, Hesse P, Schulte-Korne G, Strauch K, Remschmidt $\mathrm{H}$. Evidence for the involvement of genetic variation in the oxytocin receptor gene (OXTR) in the etiology of autistic disorders on high-functioning level. Am J Med Genet B Neuropsychiatr Genet 2010;153B:629-639.

66. Gregory SG, Connelly JJ, Towers AJ, Johnson J, Biscocho D, Markunas $\mathrm{CA}$, et al. Genomic and epigenetic evidence for oxytocin receptor deficiency in autism. BMC Med 2009;7:62.

67. Honekopp J. Digit ratio 2D:4D in relation to autism spectrum disorders, empathizing, and systemizing: a quantitative review. Autism Res 2012;5:221-230.

68. Teatero ML, Netley C. A critical review of the research on the extreme male brain theory and digit ratio (2D:4D). J Autism Dev Disord 2013; 43:2664-2676.

69. Krajmer P, Spajdel M, Kubranska A, Ostatnikova D. 2D:4D finger ratio in Slovak autism spectrum population. Bratisl Lek Listy 2011;112:377379.

70. Manning JT, Baron-Cohen S, Wheelwright S, Sanders G. The 2nd to 4th digit ratio and autism. Dev Med Child Neurol 2001;43:160-164.

71. Manning JT, Scutt D, Wilson J, Lewis-Jones DI. The ratio of 2nd to 4th digit length: a predictor of sperm numbers and concentrations of testosterone, luteinizing hormone and oestrogen. Hum Reprod 1998;13: 3000-3004.

72. Ingudomnukul E, Baron-Cohen S, Wheelwright S, Knickmeyer R. Elevated rates of testosterone-related disorders in women with autism spectrum conditions. Horm Behav 2007;51:597-604.

73. Takagishi H, Takahashi T, Yamagishi T, Shinada M, Inukai K, Tanida S, et al. Salivary testosterone levels and autism-spectrum quotient in adults. Neuro Endocrinol Lett 2010;31:837-841.

74. Frayne J, Nicholson HD. Effect of oxytocin on testosterone production by isolated rat Leydig cells is mediated via a specific oxytocin receptor. Biol Reprod 1995;52:1268-1273.

75. Homeida AM, Khalafalla AE. Effects of oxytocin and an oxytocin antagonist on testosterone secretion during the oestrous cycle of the goat (Capra hircus). J Reprod Fertil 1990;89:347-350.

76. Gossen A, Hahn A, Westphal L, Prinz S, Schultz RT, Grunder G, et al. Oxytocin plasma concentrations after single intranasal oxytocin administration - a study in healthy men. Neuropeptides 2012;46:211-215.

77. Arsenijevic Y, Tribollet E. Region-specific effect of testosterone on oxytocin receptor binding in the brain of the aged rat. Brain Res 1998;785: 167-170.

78. Breton C, Zingg HH. Expression and region-specific regulation of the oxytocin receptor gene in rat brain. Endocrinology 1997;138:1857-1862.

79. Johnson AE, Coirini H, McEwen BS, Insel TR. Testosterone modulates oxytocin binding in the hypothalamus of castrated male rats. Neuroendocrinology 1989;50:199-203.

80. Insel TR, Young L, Witt DM, Crews D. Gonadal steroids have paradoxical effects on brain oxytocin receptors. J Neuroendocrinol 1993;5: 619-628.

81. Tribollet E, Audigier S, Dubois-Dauphin M, Dreifuss JJ. Gonadal steroids regulate oxytocin receptors but not vasopressin receptors in the brain of male and female rats. An autoradiographical study. Brain Res 1990;511:129-140.

82. Kret ME, De Dreu CK. Oxytocin-motivated ally selection is moderated by fetal testosterone exposure and empathic concern. Front Neurosci 2013;7:1.

83. Dawson G, Estes A, Munson J, Schellenberg G, Bernier R, Abbott R. Quantitative assessment of autism symptom-related traits in probands and parents: Broader Phenotype Autism Symptom Scale. J Autism Dev Disord 2007;37:523-536.

84. Pickles A, Starr E, Kazak S, Bolton P, Papanikolaou K, Bailey A, et al. Variable expression of the autism broader phenotype: findings from extended pedigrees. J Child Psychol Psychiatry 2000;41:491-502.

85. Schwichtenberg AJ, Young GS, Sigman M, Hutman T, Ozonoff S. Can family affectedness inform infant sibling outcomes of autism spectrum disorders? J Child Psychol Psychiatry 2010;51:1021-1030.

86. Badcock C, Crespi B. Imbalanced genomic imprinting in brain development: an evolutionary basis for the aetiology of autism. J Evol Biol 2006; 19:1007-1032.

87. Barraza JA, Zak PJ. Empathy toward strangers triggers oxytocin release and subsequent generosity. Ann N Y Acad Sci 2009;1167:182-189.

88. Morhenn VB, Park JW, Piper E, Zak P. Monetary sacrifice among strangers is mediated by endogenous oxytocin release after physical contact. Evol Hum Behav 2008;29:375-383.

89. McEwen BB. Brain-fluid barriers: relevance for theoretical controversies regarding vasopressin and oxytocin memory research. Adv Pharmacol 2004;50:531-592, 655-708. 
90. Churchland PS, Winkielman P. Modulating social behavior with oxytocin: how does it work? What does it mean? Horm Behav 2012;61: 392-399.

91. Fecteau S, Mottron L, Berthiaume C, Burack JA. Developmental changes of autistic symptoms. Autism 2003;7:255-268.

92. Elabd C, Cousin W, Upadhyayula P, Chen RY, Chooljian MS, Li J, et al. Oxytocin is an age-specific circulating hormone that is necessary for muscle maintenance and regeneration. Nat Commun 2014;5:4082. 